\title{
Positive behavioral contrast as a function of time-out duration when pigeons peck keys on a within-session procedure
}

\author{
FRANCES K. MCSWEENEY and CAM L. MELVILLE \\ Washington State University, Pullman, Washington
}

\begin{abstract}
Three pigeons pecked keys for food reinforcers delivered by multiple variable interval variable interval schedules in the first part of each session (baseline) and by multiple variable interval extinction schedules in the second part of each session (contrast). The variable interval schedules delivered reinforcers after an average of $4 \mathrm{~min}$ or $30 \mathrm{sec}$ in different conditions. The duration of a time-out between the components varied in five steps from 5 to 120 sec. Positive contrast occurred for all time-out durations in both experiments. That is, the rate of responding emitted during the constant, variable interval component was greater during the contrast than during the baseline schedules. The size of contrast did not change systematically with changes in timeout duration. These results violate most theories of contrast. They are compatible with the idea that animals integrate reinforcers over intervals longer than 2 min.
\end{abstract}

Positive behavioral contrast is an increase in the rate of responding emitted during a constant component of a multiple schedule with a worsening of the conditions of reinforcement in the other component. Positive contrast is usually studied by comparing responding during a baseline schedule, in which both components provide the same conditions of reinforcement, with responding during a contrast schedule, in which one component is held constant (the constant component) and the other component is changed to extinction (the changing component).

Most theories of contrast predict that contrast will decrease in size if a time-out is interposed between the components of the multiple schedule. During a time-out, the stimuli that signal the components are omitted and no reinforcers are delivered. The theories differ in exactly how they make that prediction.

Rachlin (1973) attributes positive contrast to the summation of responses controlled by the stimulus-reinforcer relation (classically conditioned responses) with responses controlled by the response-reinforcer relation (operantly conditioned responses). Operantly conditioned responses occur whenever a response is required to produce reinforcement. Classically conditioned responses are excited by a transition from a stimulus that signals lower valued reinforcers to a stimulus that signals higher valued reinforcers. These classically conditioned responses may be recorded with or may facilitate operantly conditioned responses.

This research was supported by NIMH Grant MH42466. The authors would like to thank John Hinson for his helpful comments on an earlier draft of this manuscript. Reprint requests should be sent to Frances $K$. McSweeney, Department of Psychology, Washington State University, Pullman, WA 99164-4820.
During the baseline schedule, operantly conditioned responses occur during both components because responses produce reinforcers. No classically conditioned responses occur because the two components provide identical rates of reinforcement. During the contrast schedule, operantly conditioned responses occur during the constant component because responses still produce reinforcers. Classically conditioned responses also occur because the appearance of the constant component represents a transition from a stimulus that signals a lower valued reinforcer (extinction in the changing component) to a stimulus that signals a higher valued reinforcer (a schedule of reinforcement in the constant component). If classically conditioned responses facilitate operantly conditioned responses, then response rates will be higher during the constant component of the contrast schedule (operantly plus classically conditioned responses) than during the constant component of the baseline schedule (operantly conditioned responses only) and positive contrast will be observed.

Interposing a time-out between components should eliminate contrast because it eliminates transitions between stimuli of different values. Eliminating value transitions removes classically conditioned responding from the constant component of the contrast schedule. Responding during that component should decrease until it equals the rate emitted during the constant component of the baseline schedule (operantly conditioned responses only).

Theories proposed by Herrnstein (1970) and McSweeney (1987) also predict that interposing a timeout will eliminate contrast. However, they predict that the rate of responding emitted during the constant component of the baseline schedule will increase until it equals the rate emitted during the constant component of the contrast schedule. 
According to Herrnstein (1970), the rate of responding emitted in either component of a multiple schedule is inversely related to the rate of reinforcement obtained from the other component. As a result, rates of constantcomponent responding are lower during the baseline schedule when the changing component provides some reinforcers than during the contrast schedule when the changing component provides no reinforcers. As the duration of a time-out between the components increases, the interaction between the components decreases. With decreasing interaction, the effect of changing-component reinforcers on constant-component responding decreases and constant-component response rates rise during the baseline schedule. If the time-out is long enough, no interaction occurs between the components of the baseline schedule, and constant-component responding equals constant-component responding during the contrast schedule when no changing-component reinforcers are presented.

McSweeney (1987) attributed contrast to suppression by delayed reinforcement. She argued that reinforcers have two effects on behavior. They increase the frequency of responses that they follow quickly, and they suppress responses that they follow after a delay. During the baseline schedule, reinforcers delivered in the changing component of the multiple schedule are delayed after responding in the constant component. Therefore, they suppress that responding. During the contrast schedule, reinforcers are removed from the changing component. They no longer suppress constant-component responding. Constant-component response rates rise, creating positive contrast.

According to McSweeney (1987), the suppressive effect of a reinforcer does not extend indefinitely in time. It is maximal at some particular point and then decreases as the delay to reinforcement increases further. Therefore, as the duration of a time-out between the components increases, a point should be reached at which reinforcers delivered during the changing component no longer suppress responding during the constant component. Constant-component response rates in the baseline schedule should rise until they equal constant-component response rates in the contrast schedule when no reinforcers are delivered during the changing component.

Few studies have examined these predictions. The existing data are contradictory and difficult to interpret. For example, Mackintosh, Little, and Lord (1972) reported results that may be consistent with the theories. In their study, subjects were exposed to 90 -sec presentations of a variable interval (VI) 1-min schedule separated by either 10- or 60-sec time-outs. In other conditions, subjects were exposed to 90 -sec presentations of a VI 1 -min schedule alternating with 90 -sec presentations of extinction (ext). Again, 10 - or 60 -sec time-outs separated all presentations. Mackintosh et al. concluded that contrast occurred for the 10-sec but not for the 60 -sec time-outs because responding was faster during the VI schedule when it alternated with extinction than when it alternated with itself only when 10-sec time-outs separated the components.

However, Mackintosh et al.'s (1972) results are inconclusive. Contrast may have failed for the 60 -sec time-outs because of a ceiling effect. Subjects responded as fast as 120 responses per minute during the VI schedule that alternated with itself when the 60-sec time-out was used. Subjects may not have been able to respond faster when extinction was introduced. Subjects responded at approximately 50 responses per minute when the VI schedule alternated with itself and the 10-sec time-out was used. Subjects could easily increase their response rates when extinction was introduced.

Bloomfield (1967) reported results that apparently contradict the theories. He placed pigeons on the following schedules, presented in the following order: VI, multiple VI ext, VI, and multiple VI VI. Components of the multiple schedules occurred on alternate days. Response rates were higher during the VI component of the multiple VI ext schedule than they had been during the preceding VI schedule, suggesting that contrast survives a 24-h timeout between the components. However, responding during the VI component did not decrease again when the multiple schedule was replaced by the second VI. Therefore, the increase in responding may have been a fluctuation in responding over time rather than behavioral contrast. Large fluctuations in response rates are frequently found when multiple schedules are used (e.g., McSweeney, Dougan, Higa, \& Farmer, 1986; Spealman \& Gollub, 1974).

Timberlake has also shown that animals may integrate rewards over intervals as long as 16 min (e.g., Lucas, Gawley, \& Timberlake, 1988; Timberlake, Gawley, \& Lucas, 1987). In a procedure similar to that used to study behavioral contrast, Lucas et al. (1988) measured the consumption of a $0.15 \%$ saccharin solution followed by a $32 \%$ sucrose solution. Saccharin intake was suppressed relative to a control group that received two presentations of the saccharin solution when the interval between the delivery of the two solutions was 4 or $16 \mathrm{~min}$ but not when it was $32 \mathrm{~min}$. Such data suggest that this anticipatory contrast survives relatively long delays between the presentations of the different conditions of reinforcement.

The present experiment examines the size of multipleschedule behavioral contrast as a function of time-out duration when pigeons peck keys. The first part of the study examines responding when a multiple VI 4-min VI 4-min baseline schedule is used. Because the size of contrast did not change with time-out duration, a second baseline schedule (multiple VI 30-sec VI 30-sec) was also conducted. The choice of the baseline schedule may influence the size of contrast (e.g., McSweeney et al., 1986).

The present experiment uses a within-session method of measuring contrast. Within-session procedures have been used occasionally in the past (e.g., Coelho de Rose, 1986; Williams, 1979), but most studies of contrast use across-sessions procedures. Across-sessions procedures 
modify the reinforcement provided by one component across successive phases from baseline to contrast and then back to baseline (e.g., McSweeney et al., 1986). Withinsession procedures measure contrast and baseline within single sessions.

The within-session procedure was developed to deal with two problems that have discouraged functional studies of contrast. First, the across-sessions procedure requires many sessions to conduct. Each measurement of contrast requires exposure to a multiple schedule in each of three phases, with each phase lasting 30 to 40 sessions. Second, fluctuations in responding that occur over these long periods confound the measurement of contrast. Rates of responding may double from one baseline schedule to its recovery (e.g., McSweeney et al., 1986; Spealman \& Gollub, 1974), severely limiting the accuracy of quantitative statements.

The present within-session procedure addresses these problems. It delivers a baseline schedule in the first half of the session and a contrast schedule in the second half. Because it measures baseline and contrast within single sessions, it reduces both the amount of time required to measure contrast and the fluctuations in responding that occur over time. The details of the present within-session procedure (e.g., order of components, session length) have been empirically derived to produce orderly results that resemble those produced by the across-sessions procedure (cf. McSweeney, 1982; McSweeney \& Melville, 1988). Fluctuations in response rates across the session do not confound the measurement of contrast by this procedure. Rates of responding emitted during the first half of a session do not differ from those emitted during the second half when the rate of reinforcement is held constant across the session (McSweeney, Hatfield, \& Allen, 1990).

\section{METHOD}

\section{Subjects}

Three experimentally experienced pigeons served as subjects. They were maintained at approximately $85 \%$ of their free-feeding body weights.

\section{Apparatus}

The apparatus was a three-key experimental enclosure for pigeons, measuring $32.5 \times 30.5 \times 35.5 \mathrm{~cm}$. Three $2.5-\mathrm{cm}$ diameter response keys were located $23.5 \mathrm{~cm}$ above the floor and $7.5 \mathrm{~cm}$ apart. The left and right keys were located $6.5 \mathrm{~cm}$ from the left and right walls, respectively. Two $6.5 \times 4 \mathrm{~cm}$ openings allowed access to food magazines that contained mixed grain. They were located $9.5 \mathrm{~cm}$ below the left and right keys.

The experimental panel was housed in a sound-attenuating chamber. A ventilating fan masked noises from outside the chamber. Experimental events were programmed by a SYM microcomputer located in another room.

\section{Procedure}

The subjects were placed directly onto the experimental procedure because they had pecked keys for food reinforcers in previous experiments. The experimental session was divided into two parts that were conducted successively. The first part (baseline)
Table 1

Time-Out Durations (in seconds) Conducted and Number of Components Presented per Session in the Order Conducted

\begin{tabular}{cc}
\hline Time-Out Duration & $\begin{array}{c}\text { Number of Components } \\
\text { per Session }\end{array}$ \\
\hline 10 & 20 \\
60 & 12 \\
5 & 20 \\
30 & 16 \\
120 & 8 \\
\hline
\end{tabular}

presented a multiple VI 4-min VI 4-min schedule. The second part (contrast) presented a multiple VI 4-min ext schedule. A white light appeared on the left key during the component listed first, and a green light appeared during the component listed second. Each component was $60 \mathrm{sec}$ long, and components alternated. Reinforcers were obtained by pecking the left key. They consisted of $5 \mathrm{sec}$ of access to the left magazine, which contained mixed grain.

A time-out, during which the keylight was extinguished and no reinforcers were delivered, separated the components. Table 1 lists the time-out durations that were used in their order of presentation. Table 1 also contains the number of components that were presented per session. The number varied across experimental conditions to keep the sessions similar in length.

All reinforcers were scheduled according to a 25 -interval series constructed according to the procedure outlined in Fleshler and Hoffman (1962). Reinforcers that were scheduled but not collected before a component changed were held over for collection during the next presentation of that component. Sessions were conducted once daily, 5 to 6 times per week. A houselight illuminated the chamber throughout the session. The first condition was conducted for 35 sessions; each of the other conditions was conducted for 30 sessions. Thirty sessions are more than enough to yield stable data when pigeons peck keys for food reinforcers delivered by positive contrast procedures (e.g., McSweeney, 1982).

After these schedules had been conducted, the whole experiment was repeated. This time, a multiple VI 30-sec VI 30-sec schedule was presented during the baseline phase of the session and a multiple VI 30-sec ext schedule appeared in the contrast phase. All other procedural details were the same as those listed above.

\section{RESULTS}

Table 2 presents the rates of responding (pecks per minute) for each subject and for the mean of all subjects responding on each component, and during the time-outs, for each multiple VI 4-min VI 4-min or multiple VI 4min ext schedule. The component in which the rate of reinforcement was held constant from the baseline to the contrast schedule has been labeled the constant component. The component in which the reinforcement changed has been labeled the changing component. Response rates were calculated by dividing the number of pecks emitted during a component or time-out by the time for which that component or time-out was available. The time of magazine presentation was excluded from all relevant calculations. The results are the means of the rates emitted during the last five sessions of exposure to each condition.

Table 2 shows that the rates of responding emitted during the changing components decreased for all subjects, responding at all time-out durations, when ext replaced the VI 4-min schedule. Table 2 also shows that positive 
Table 2

Rates of Responding in Responses per Minute During Each Component and During the Time-Outs for Each Multiple VI 4-min VI4-min and Multiple VI 4-min Extinction Schedule

\begin{tabular}{|c|c|c|c|c|c|c|c|c|c|}
\hline \multirow[b]{3}{*}{ Duration* } & \multirow[b]{3}{*}{ Component } & \multicolumn{8}{|c|}{ Subject } \\
\hline & & \multicolumn{2}{|c|}{5964} & \multicolumn{2}{|c|}{3174} & \multicolumn{2}{|c|}{2458} & \multicolumn{2}{|c|}{ Mean } \\
\hline & & Baseline & Contrast & Baseline & Contrast & Baseline & Contrast & Baseline & Contrast \\
\hline 5 & $\begin{array}{l}\text { Constant } \\
\text { Changing } \\
\text { Time-out }\end{array}$ & $\begin{array}{l}46.8 \\
35.5 \\
14.6\end{array}$ & $\begin{array}{l}53.4 \\
10.1 \\
19.7\end{array}$ & $\begin{array}{l}26.8 \\
23.5 \\
19.0\end{array}$ & $\begin{array}{l}41.0 \\
11.8 \\
18.7\end{array}$ & $\begin{array}{r}25.6 \\
37.8 \\
6.0\end{array}$ & $\begin{array}{l}38.6 \\
12.2 \\
20.5\end{array}$ & $\begin{array}{l}33.1 \\
32.3 \\
13.2\end{array}$ & $\begin{array}{l}44.3 \\
11.4 \\
19.6\end{array}$ \\
\hline 10 & $\begin{array}{l}\text { Constant } \\
\text { Changing } \\
\text { Time-out }\end{array}$ & $\begin{array}{r}57.2 \\
42.0 \\
1.0\end{array}$ & $\begin{array}{r}73.0 \\
11.6 \\
1.7\end{array}$ & $\begin{array}{r}26.9 \\
39.7 \\
0.6\end{array}$ & $\begin{array}{r}50.2 \\
10.4 \\
0.9\end{array}$ & $\begin{array}{r}44.6 \\
50.6 \\
1.7\end{array}$ & $\begin{array}{r}65.4 \\
21.8 \\
2.3\end{array}$ & $\begin{array}{r}42.9 \\
44.1 \\
1.1\end{array}$ & $\begin{array}{r}62.9 \\
14.6 \\
1.6\end{array}$ \\
\hline 30 & $\begin{array}{l}\text { Constant } \\
\text { Changing } \\
\text { Time-out }\end{array}$ & $\begin{array}{r}44.4 \\
31.0 \\
0.9\end{array}$ & $\begin{array}{r}61.5 \\
9.6 \\
1.9\end{array}$ & $\begin{array}{l}35.3 \\
29.8 \\
13.6\end{array}$ & $\begin{array}{l}47.4 \\
14.8 \\
15.8\end{array}$ & $\begin{array}{r}44.1 \\
60.7 \\
0.7\end{array}$ & $\begin{array}{r}74.1 \\
9.7 \\
3.0\end{array}$ & $\begin{array}{r}41.3 \\
40.5 \\
5.1\end{array}$ & $\begin{array}{r}61.0 \\
11.4 \\
6.9\end{array}$ \\
\hline 60 & $\begin{array}{l}\text { Constant } \\
\text { Changing } \\
\text { Time-out }\end{array}$ & $\begin{array}{r}49.7 \\
33.1 \\
0.2\end{array}$ & $\begin{array}{r}66.7 \\
21.9 \\
1.2\end{array}$ & $\begin{array}{r}31.7 \\
23.5 \\
0.2\end{array}$ & $\begin{array}{r}41.9 \\
3.9 \\
0.3\end{array}$ & $\begin{array}{r}46.9 \\
51.7 \\
0.5\end{array}$ & $\begin{array}{r}63.2 \\
9.2 \\
0.4\end{array}$ & $\begin{array}{r}42.8 \\
36.1 \\
0.3\end{array}$ & $\begin{array}{r}57.3 \\
11.7 \\
0.6\end{array}$ \\
\hline 120 & $\begin{array}{l}\text { Constant } \\
\text { Changing } \\
\text { Time-out }\end{array}$ & $\begin{array}{r}39.3 \\
32.5 \\
4.8 \\
\end{array}$ & $\begin{array}{r}45.5 \\
14.6 \\
7.1 \\
\end{array}$ & $\begin{array}{r}29.9 \\
16.6 \\
9.9 \\
\end{array}$ & $\begin{array}{r}32.1 \\
9.6 \\
15.0 \\
\end{array}$ & $\begin{array}{r}24.6 \\
48.2 \\
2.0 \\
\end{array}$ & $\begin{array}{r}63.2 \\
32.9 \\
3.4\end{array}$ & $\begin{array}{r}31.3 \\
32.4 \\
5.5\end{array}$ & $\begin{array}{r}46.9 \\
19.0 \\
8.5\end{array}$ \\
\hline
\end{tabular}

contrast occurred. That is, the rates of responding emitted during the constant components increased for all subjects, responding at all time-out durations, when ext replaced the VI 4-min schedule in the changing component.

Rates of responding did not change as a function of time-out duration for either component of either schedule. One-way within-subject analyses of variance showed that response rates did not change as a function of timeout duration for the constant component of the contrast schedule $[F(4,8)=3.21, p<.08]$, the constant component of the baseline schedule $[F(4,8)=2.26, p<.15]$, the changing component of the contrast schedule $[F(4,8)$ $=0.60, p<.68]$, or the changing component of the baseline schedule $[F(4,8)=1.97, p<.19]$.
Rates of responding during the time-outs were low relative to the rates during the components for all components except extinction for the 5-sec time-out duration. Response rates during the time-outs also changed significantly with time-out duration for both the baseline $[F(4,8)=5.24$, $p<.02]$ and the contrast $[F(4,8)=10.05, p<.01]$ schedules. Response rates were significantly different for the 5 -sec and 10-sec $[t(2)=119.91, p<.01]$ and for the 5 -sec and 60-sec $[t(2)=33.18, p<.01]$ time-outs during the contrast schedules. Response rates were significantly different for the 5 -sec and 120 -sec time-outs during the baseline schedules $[t(2)=4.18, p<.05]$.

Table 3 presents the rates of responding (pecks per minute) for each subject and for the mean of all subjects responding during each component, and during the time-

Table 3

Rates of Responding in Responses per Minute During Each Component and During the Time-Outs of the Multiple VI 30-sec VI 30-sec and Multiple VI 30-sec Extinction Schedules

\begin{tabular}{|c|c|c|c|c|c|c|c|c|c|}
\hline \multirow[b]{3}{*}{ Duration* } & \multirow[b]{3}{*}{ Component } & \multicolumn{8}{|c|}{ Subject } \\
\hline & & \multicolumn{2}{|c|}{5964} & \multicolumn{2}{|c|}{3174} & \multicolumn{2}{|c|}{2458} & \multicolumn{2}{|c|}{ Mean } \\
\hline & & Baseline & Contrast & Baseline & Contrast & Baseline & Contrast & Baseline & Contrast \\
\hline 5 & $\begin{array}{l}\text { Constant } \\
\text { Changing }\end{array}$ & $\begin{array}{l}61.9 \\
52.3\end{array}$ & $\begin{array}{r}77.7 \\
7.5\end{array}$ & $\begin{array}{l}57.1 \\
44.6\end{array}$ & $\begin{array}{r}73.6 \\
0.9\end{array}$ & $\begin{array}{l}37.2 \\
60.1\end{array}$ & $\begin{array}{l}45.6 \\
16.4\end{array}$ & $\begin{array}{l}52.1 \\
52.3\end{array}$ & $\begin{array}{r}65.6 \\
8.3\end{array}$ \\
\hline & Time-out & 2.4 & 12.5 & 3.4 & 3.7 & 1.9 & 8.5 & 2.6 & 8.3 \\
\hline 10 & $\begin{array}{l}\text { Constant } \\
\text { Changing } \\
\text { Time-out }\end{array}$ & $\begin{array}{r}65.7 \\
44.5 \\
1.3\end{array}$ & $\begin{array}{r}75.8 \\
4.7 \\
0.9\end{array}$ & \begin{tabular}{r|r|}
53.8 \\
37.8 \\
1.3
\end{tabular} & $\begin{array}{r}61.2 \\
0.7 \\
1.1\end{array}$ & $\begin{array}{r}66.3 \\
80.2 \\
2.8\end{array}$ & $\begin{array}{l}91.0 \\
44.8 \\
12.1\end{array}$ & $\begin{array}{r}61.9 \\
54.2 \\
1.8\end{array}$ & $\begin{array}{r}76.0 \\
16.7 \\
4.7\end{array}$ \\
\hline 30 & $\begin{array}{l}\text { Constant } \\
\text { Changing } \\
\text { Time-out }\end{array}$ & $\begin{array}{r}75.5 \\
55.4 \\
0.4\end{array}$ & $\begin{array}{r}78.9 \\
11.8 \\
0.3\end{array}$ & $\begin{array}{r}51.6 \\
65.0 \\
0.8\end{array}$ & $\begin{array}{r}65.2 \\
12.1 \\
0.7\end{array}$ & $\begin{array}{r}53.3 \\
58.8 \\
0.6\end{array}$ & $\begin{array}{r}63.8 \\
16.5 \\
2.0\end{array}$ & $\begin{array}{r}60.1 \\
59.7 \\
0.6\end{array}$ & $\begin{array}{r}69.3 \\
13.5 \\
1.0\end{array}$ \\
\hline 60 & $\begin{array}{l}\text { Constant } \\
\text { Changing } \\
\text { Time-out }\end{array}$ & $\begin{array}{r}73.7 \\
54.4 \\
0.3\end{array}$ & $\begin{array}{r}89.6 \\
24.5 \\
0.1\end{array}$ & $\begin{array}{r}72.3 \\
79.9 \\
0.4\end{array}$ & $\begin{array}{r}76.5 \\
15.9 \\
0.6\end{array}$ & $\begin{array}{r}50.3 \\
82.5 \\
0.4\end{array}$ & $\begin{array}{r}73.3 \\
52.5 \\
2.3\end{array}$ & $\begin{array}{r}65.4 \\
72.3 \\
0.4\end{array}$ & $\begin{array}{r}79.8 \\
31.0 \\
1.0\end{array}$ \\
\hline 120 & $\begin{array}{l}\text { Constant } \\
\text { Changing } \\
\text { Time-out }\end{array}$ & $\begin{array}{r}62.9 \\
47.9 \\
0.1 \\
\end{array}$ & $\begin{array}{r}81.9 \\
17.9 \\
0.2 \\
\end{array}$ & $\begin{array}{r}56.5 \\
64.0 \\
0.5 \\
\end{array}$ & $\begin{array}{r}76.4 \\
15.7 \\
0.1 \\
\end{array}$ & $\begin{array}{r}71.2 \\
71.3 \\
1.1 \\
\end{array}$ & $\begin{array}{r}74.7 \\
61.3 \\
1.0 \\
\end{array}$ & $\begin{array}{r}63.5 \\
61.1 \\
0.5 \\
\end{array}$ & $\begin{array}{r}77.7 \\
31.6 \\
0.5 \\
\end{array}$ \\
\hline
\end{tabular}

*In seconds. 
outs, of each multiple VI 30-sec VI 30-sec or multiple VI 30-sec ext schedule. Response rates were calculated and reported as they were for Table 2 .

Table 3 shows that the rates of responding emitted during the changing components decreased for all subjects, responding at all time-out durations, when extinction replaced the VI 30-sec schedule. Table 3 also shows that positive contrast occurred. That is, the rates of responding emitted during the constant components increased for all subjects, responding at all time-out durations, when extinction replaced the VI 30-sec schedule in the changing component.

Rates of responding did not change significantly as a function of time-out duration for any of the components. One-way within-subject analyses of variances showed that responding did not change significantly with changes in time-out duration for the constant component of the contrast schedule $[F(4,8)=0.86, p<.53]$, the constant component of the baseline schedule $[F(4,8)=0.71$, $p<.61]$, the changing component of the contrast schedule $[F(4,8)=3.04, p<.09]$, or the changing component of the baseline schedule $[F(4,8)=1.49, p<.29]$.

Table 3 shows that the rates of responding during the time-outs were low relative to the rates during the components for all components except extinction for the 5sec time-out duration. The rates of responding emitted during the time-outs also changed significantly with timeout duration for the baseline $[F(4,8)=9.12, p<.01]$ but not for the contrast $[F(4,8)=3.11, p<.08]$ schedules. During the baseline schedules, response rates during the 5-sec time-outs were significantly different from those during the $30-\sec [t(2)=5.47, p<.03]$ and 60 $\sec [t(2)=5.24, p<.04]$ time-outs. Response rates during the 30 -sec time-outs were significantly different from those during the 120 -sec time-outs $[t(2)=5.06$, $p<.04]$.

Figure 1 presents the mean size of contrast in responses per minute plotted as a function of time-out duration in seconds. The size of contrast was calculated by subtracting the rate of responding emitted during the constant component of the baseline schedule from the rate of responding emitted during the same component of the contrast schedule. The circles and solid line represent the results for the multiple VI 4-min VI 4-min and multiple VI 4min ext schedules. The triangles and dashed line represent the results for the multiple VI 30-sec VI 30-sec and multiple VI 30-sec ext schedules. Calculations were based on the data reported in Tables 2 and 3. The results are those for the mean of all subjects. One-way within-subject analyses of variance showed that the size of contrast did not change significantly with time-out duration for either the multiple VI 4-min VI 4-min $[F(4,8)=0.51, p<.73]$ or the multiple VI $30-\sec$ VI $30-\sec [F(4,8)=0.19$, $p<.94]$ baseline schedules.

\section{DISCUSSION}

The present procedure exerted good control over behavior. The rates of responding emitted during the chang-

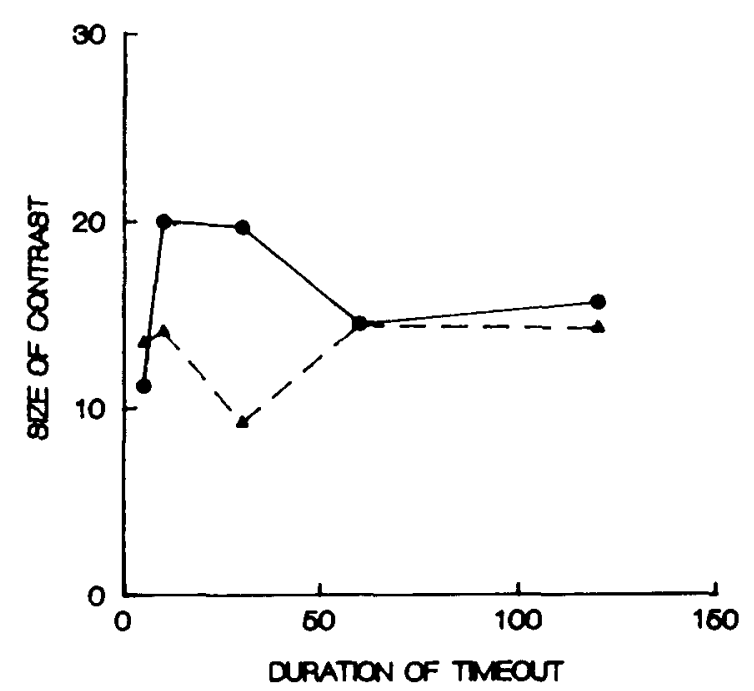

Figure 1. Positive contrast in responses per minute plotted as a function of time-out duration in seconds. The size of contrast was measured by subtracting the rate of responding emitted during the constant component of the bescline schedule from the rate of responding emitted during the same component of the contrast schedule. The circle and solid line represent the results for the multiple VI 4-min VI 4-min and multiple VI 4-min extinction schedule. The triangles and dashed line represent the results for the multiple VI $30-$ sec VI $30-\mathrm{sec}$ and multiple VI $30-\mathrm{sec}$ extinction schedules. The results are those for the mean of all subjects.

ing component decreased when extinction replaced the VI schedule. Behavioral contrast also occurred. That is, the rates of responding emitted during the constant component increased when extinction replaced the VI schedule in the changing component. These changes in response rates occurred consistently, for all subjects, responding at all time-out durations in both experiments.

Subjects also discriminated the presence of the timeouts and their durations. The mean response rates emitted during the time-outs were considerably lower than those emitted during the components for all components except extinction for the 5-sec time-outs. Response rates during the time-outs also changed significantly with changes in time-out duration in both experiments.

Even though they are orderly, the present results contradict all of the theories of contrast. As argued earlier, Rachlin (1973) predicts that the rates of responding emitted during the constant component of the contrast schedule should decrease with increases in time-out duration. Herrnstein (1970) and McSweeney (1987) predict that the rates of responding emitted during the constant component of the baseline schedule should increase with increases in time-out duration. The rates of constantcomponent responding during the baseline and contrast schedules did not change significantly as a function of time-out duration for either the multiple VI 4-min VI 4-min or the multiple VI 30-sec VI 30-sec baseline schedules.

It might be argued that responding did not change significantly because of the weakness of the present statistical tests. Only 3 subjects served in this experiment, and 
the changes in the rates of responding approached significance when the multiple VI 4-min VI 4-min baseline was used (see Table 2). However, even the trends in the data violate the theories. The rates of constant-component responding increased and then decreased with increases in time-out duration for both the baseline and contrast schedules in both Tables 2 and 3. None of the theories predicts either that constant-component response rates will change during both the baseline and contrast schedules or that response rates will change as a bitonic function of time-out duration. Therefore, even the trends in the data contradict the theories.

Figure 1 shows that the size of contrast does not decrease with increases in time-out duration. These results also violate all three theories. The results are particularly surprising because the present experiment may have been biased in favor of confirming the theories. Larger contrast logically should be (Rachlin, 1973) and empirically has been (Williams, 1988) observed for better discrimination between the components of the multiple schedules. Discrimination might have been better for shorter than for longer time-outs because subjects had more extinction components per session (see Table 1) and therefore more exposure to extinction for shorter components. Poorer discrimination for longer time-outs should have made the observation of contrast less likely for longer time-outs, making confirmation of the theories even more likely.

Tables 2 and 3 show that discrimination changes somewhat, but not significantly, with time-out duration. To measure discrimination, a discrimination ratio was calculated for each subject responding on each contrast schedule by dividing the rate of responding emitted during the extinction component by the sum of the rates of responding emitted during both components. This ratio would be 0 if the subject discriminated perfectly between the components and 0.50 if the subject did not discriminate at all. The medians of these discrimination ratios for the multiple VI 4-min ext schedules were $0.22,0.17,0.14$, 0.13 , and 0.24 for the 5-, 10-, 30-, 60-, and 120-sec timeouts, respectively. The medians for the multiple VI 30 sec ext schedules were $0.09,0.06,0.16,0.21$, and 0.18 for the same time-out durations. The expected trend appears in the data. Discrimination was somewhat poorer for the longer than for the shorter time-outs, but these differences were not statistically significant. A Friedman nonparametric analysis of variance showed that discrimination ratios did not change significantly with time-out duration for the multiple VI 4-min ext schedule (Friedman test statistic $=2.87, d f=4, p<.58$ ). Discrimination ratios fell just short of significance for the multiple VI 30-sec ext schedule (Friedman test statistic $=9.20$, $d f=4, p<.06$ ).

Because the present data seriously challenge the theories of contrast, three ways of reconciling the data with the theories will be considered. First, the results might be reconciled with the theories if subjects treated the timeouts as a second extinction component. In that case, the time-out itself, not the following extinction component, would have produced contrast and contrast would not disappear as the time-out lengthened. Subjects might treat a time-out as an extinction component because no reinforcers are delivered during it. In fact, a dark key associated with extinction (time-out) has produced contrast when alternated with a schedule of reinforcement (Kaufman \& Baron, 1968; Kodera \& Rilling, 1976; Reynolds, 1961; Sadowsky, 1973).

The present subjects did not treat the time-outs as extinction components, however. If they had, then lengthening the time-outs should have produced results similar to those produced by lengthening extinction. Lengthening an extinction component increases response rates and produces larger contrast during constant-duration constant components (e.g., Ettinger \& Staddon, 1982; Wilton \& Clements, 1971). Lengthening the present time-outs did not have a significant effect on either the constantcomponent response rates or the size of contrast.

Second, the present results could be partially reconciled with the theories if the time-outs were too short to produce an effect. The present time-outs were chosen for several reasons. They exceed the duration of the time-outs that appeared to have eliminated contrast in a previous experiment (Mackintosh et al., 1972). They are longer than pigeons' short-term memory is assumed to be. Pigeons' memory for neutral stimuli may decline rapidly over periods as short as $5 \mathrm{sec}$ (e.g., Blough, 1959; Farthing, Wagner, Gilmour, \& Waxman, 1977). The interaction between the components (Herrnstein, 1970) and suppression by reinforcement (McSweeney, 1987) are also assumed to decline rapidly over the present intervals. For example, the size of positive keypeck contrast decreases substantially when the duration of the components of a multiple schedule increases from $5 \mathrm{sec}$ to 2 or $3 \mathrm{~min}$ (e.g., McSweeney, 1982). Although it is beyond the scope of this discussion, decreases in the interaction between the components or in suppression by reinforcement may account for this decline. If they do, then these factors must change significantly over the intervals of time used in the present study.

The present experiments should be replicated using longer time-outs. If contrast occurred for relatively long time-outs (e.g., $10 \mathrm{~min}$ ), then changes in the interactions between the components or in suppression by reinforcement could not account for both changes in the size of contrast with component duration (short time course) and changes in the size of contrast with time-out duration (long time course). Herrnstein's and McSweeney's theories would require revision to account for these differences.

If contrast occurred when time-outs were 16 min long, but not when they were $32 \mathrm{~min}$ long, then the results would be consistent with Timberlake's findings (e.g., Lucas et al., 1988; Timberlake et al., 1987). This would show that the time course for integrating rewards has some generality across species (pigeons as well as rats), procedures (behavioral contrast as well as anticipatory contrast 
or foraging), and the absence of rewards as well as their presence. That is, the results would show that subjects integrate extinction with reinforcement over periods of time that are similar to those over which they integrate two different rewards.

Third, the data might be reconciled with the theories by restricting the theories to data collected using the across-sessions procedure for producing contrast. In that case, the present data would not apply to the theories because they were collected using a within-session procedure. There are many reasons why the within-session and across-sessions procedures might produce different results. For example, responding during the changing component is extinguished throughout training in the within-session procedure. Responding is extinguished only during the first few sessions in the across-sessions procedure. As a result, factors related to the introduction of extinction (e.g., frustration) might play a larger role in the contrast produced by the within-session procedure than in that produced by the across-sessions procedure.

The present experiment should be replicated using an across-sessions procedure to test this possibility. Until such an experiment is conducted, however, there are reasons for avoiding distinctions between the contrast produced by the two procedures.

First, parsimony dictates that distinctions should not be drawn unless there are compelling reasons to do so. Quite the contrary, past experiments have shown that the withinsession and across-sessions procedures produce similar results. On the qualitative level, both procedures produce good discrimination and strong contrast. On the quantitative level, the contrast generated by the two procedures is similar in size and changes as similar functions of an independent variable, component duration. McSweeney (1982) used an across-sessions procedure that delivered low rates of reinforcement (multiple VI 2-min VI 2-min or multiple VI 2-min ext), presented both components on the same response key, placed the discriminative stimuli on the response key, and did not impose a time-out between the components. McSweeney and Melville (1988, Experiment 3) used a within-session procedure that delivered high rates of reinforcement (multiple VI 15-sec VI 15-sec or multiple VI 15-sec ext), presented the two components on different operanda, moved the discriminative stimuli from the response key, and introduced a 3-sec time-out between the components. In spite of the many procedural differences between the studies, the mean sizes of contrast reported using the across-sessions and withinsession procedures were very similar for the three component durations studied in both experiments. They were 1.61 and 1.64 for the 5-sec components, 1.39 and 1.44 for the 30-sec components, and 1.14 and 1 .16 for the 3min components. The size of contrast was measured by dividing the rate of responding emitted during the VI component of a multiple VI ext schedule by the rate of responding emitted during the same component of a multiple VI VI schedule. Ratio measures were used instead of the difference measures reported in Figure 1 to correct for large differences in the absolute rates of respond- ing across the studies. Quantitative similarities in the contrast produced by the two procedures suggest that the same mechanism produces the two types of contrast, at least under some conditions.

Second, the theories themselves provide no rationale for restricting them to across-sessions contrast. The theories should describe the effect of changing the conditions of reinforcement provided by one component of a multiple schedule on responding emitted during the other component. The present within-session procedure fits this description. Tables 2 and 3 show that subjects did detect the changes in the rates of reinforcement provided by the changing component, and the rates of constant-component responding did change as a result. Restricting the theories to across-sessions contrast would imply that the theories are at least incomplete because they do not explain their failure with data produced by the within-session procedure.

The present results show that none of the theories describes contrast as measured by the within-session procedure over the present range of time-outs. Future experiments should extend the generality of these results by replicating them using an across-sessions procedure and a wider range of time-outs. In addition to testing the predictions of the theories, such an experiment would provide important information about the comparability of the within-session and across-sessions procedures. As argued earlier, the within-session procedure provides advantages for the study of contrast. However, more information is needed about the comparability of this procedure and the more standard across-sessions procedure before general conclusions can be drawn.

\section{REFERENCES}

Bloomfield, T. M. (1967). Some temporal properties of behavioral contrast. Journal of the Experimental Analysis of Behavior, 10, 159-164.

BLovGH, D. S. (1959). Delayed matching in the pigeon. Journal of the Experimental Analysis of Behavior, 2, 151-160.

COELHO DE ROSE, J. C. (1986). Behavioral contrast in fixed-interval components: Effects of extinction-component duration. Journal of the Experimental Analysis of Behavior, 45, 175-188.

ETtinger, R. H., Staddon, J. E. R. (1982). Behavioral competition, component duration and multiple schedule contrast. Behavioural Analysis Letters, 2, 31-38.

Farthing, G. W., Wagner, J. M., Gilmour, S., Waxman, H. M. (1977). Short-term memory and information processing in pigeons. Learning \& Motivation, 8, 520-532.

Fleshler, M., Hoffman, H. S. (1962). A progression for generating variable-interval schedules. Journal of the Experimental Analysis of Behavior, $5,529-530$.

HerRnstein, R. J. (1970). On the law of effect. Journal of the Experimental Analysis of Behavior, 13, 243-266.

KAUfMAN, A., \& BARON, A. (1968). Suppression of behavior by timeout punishment when suppression results in loss of positive reinforcement. Journal of the Experimental Analysis of Behavior, 11, 595-607.

Kodera, T. L., Rilling, M. (1976). Procedural antecedents of behavioral contrast: A re-examination of errorless learning. Journal of the Experimental Analysis of Behavior, 25, 27-42.

Lucas, G. A., Gawley, D. J., \& Timberlake, W. (1988). Anticipatory contrast as a measure of time horizons in the rat: Some methodological determinants. Animal Learning \& Behavior, 16, 377-382.

MACKINTOSH, N. J., LiTTLE, L., \& LORD, J. (1972). Some determinants 
of behavioral contrast in pigeons and rats. Learning \& Motivation, 3, 148-161.

MCSWEENEY, F. K. (1982). Positive and negative contrast as a function of component duration for key pecking and treadle pressing. Journal of the Experimental Analysis of Behavior, 37, 281-293.

MCSWEENEY, F. K. (1987). Suppression by reinforcement, a model for multiple-schedule behavioral contrast. Behavioural Processes, 15, 191-209.

MCSweeney, F. K., Dugan, J. D., Higa, J., \& Farmer, V. A. (1986). Behavioral contrast as a function of component duration and baseline rate of reinforcement. Animal Learning \& Behavior, 14, 173-183.

McSweeney, F. K., Hatfield, J., \& Allen, T. A. (1990). Withinsession responding as a function of post-session feedings. Behavioural Processes, 22, 177-186.

McSweeney, F. K., Melville, C. L. (1988). Positive contrast as a function of component duration using a within-session procedure. Behavioural Processes, 16, 21-41.

Rachlin, H. C. (1973). Contrast and matching. Psychological Review, 80, 217-234.

REYNOLDS, G. S. (1961). Behavioral contrast. Joumal of the Experimental Analysis of Behavior, 4, 57-71.

SADOWSKY, S. (1973). Behavioral contrast with timeout, blackout, or extinction as the negative condition. Journal of the Experimental Analysis of Behavior, 19, 499-507.

Spealman, R. D., Gollub, L. R. (1974). Behavioral interactions in multiple variable-interval schedules. Journal of the Experimental Analysis of Behavior, 22, 471-481.

Timberlake, W., Gawley, D. J., \& Lucas, G. A. (1987). Time horizons in rats foraging for food in temporally separated patches. Journal of Experimental Psychology: Animal Behavior Processes, 13, 302-309.

Williams, B. A. (1979). Contrast, component duration, and the following schedule of reinforcement. Journal of Experimental Psychology: Animal Behavior Processes, 5, 379-396.

Williams, B. A. (1988). The effects of stimulus similarity on different types of contrast. Animal learning \& Behavior, 16, 206-216.

Wilton, R. N., \& Clements, R. O. (1971). Behavioral contrast as a function of the duration of an immediately preceding period of extinction. Journal of the Experimental Analysis of Behavior, 16, 425-428.

(Manuscript received July 16, 1990; revision accepted for publication February 21, 1991.) 